IZA DP No. 9240

Social Responsibility in Market Interaction

Bernd Irlenbusch

David Saxler

July 2015 


\title{
Social Responsibility in Market Interaction
}

\author{
Bernd Irlenbusch \\ University of Cologne \\ and IZA \\ David Saxler \\ CGS, University of Cologne
}

Discussion Paper No. 9240

July 2015

IZA
P.O. Box 7240
53072 Bonn
Germany

\author{
Phone: +49-228-3894-0 \\ Fax: +49-228-3894-180 \\ E-mail: iza@iza.org
}

\begin{abstract}
Any opinions expressed here are those of the author(s) and not those of IZA. Research published in this series may include views on policy, but the institute itself takes no institutional policy positions. The IZA research network is committed to the IZA Guiding Principles of Research Integrity.

The Institute for the Study of Labor (IZA) in Bonn is a local and virtual international research center and a place of communication between science, politics and business. IZA is an independent nonprofit organization supported by Deutsche Post Foundation. The center is associated with the University of Bonn and offers a stimulating research environment through its international network, workshops and conferences, data service, project support, research visits and doctoral program. IZA engages in (i) original and internationally competitive research in all fields of labor economics, (ii) development of policy concepts, and (iii) dissemination of research results and concepts to the interested public.
\end{abstract}

IZA Discussion Papers often represent preliminary work and are circulated to encourage discussion. Citation of such a paper should account for its provisional character. A revised version may be available directly from the author. 


\section{ABSTRACT}

\section{Social Responsibility in Market Interaction}

A recent debate raises the question whether market interaction erodes social responsibility. In an experiment, we disentangle three major characteristics of market interaction, diffusion of responsibility, social information, and market framing, and provide evidence for how these characteristics influence behavior when trade harms uninvolved parties. We model the negative externalities from trade by reducing donations to a charity that provides meals to needy children. Our results show that diffusion of responsibility tends to encourage subjects to make purely self-interested decisions. This holds to a much larger extent if the economic transaction is framed as a market. In contrast, social information increases social responsibility in our setting. Observing the behavior of others seems to convince a substantial fraction of people to behave steadfastly, i.e., they avoid trading a good that comes with negative externalities, even if gains from trade are high.

JEL Classification: C92, D47, D62, M14

Keywords: social responsibility, diffusion of responsibility, social information, market framing, experiment

Corresponding author:

Bernd Irlenbusch

University of Cologne

Seminar of Corporate Development and Business Ethics

Albertus-Magnus-Platz

50923 Cologne

Germany

E-mail: bernd.irlenbusch@uni-koeln.de 


\section{Acknowledgments}

Financial support from the Deutsche Forschungsgemeinschaft through Grant of sub-project TP3 of the DFG-Forschergruppe 'Design and behavior', FOR1371, is gratefully acknowledged.

\section{Introduction}

The production and exchange of goods often imposes costs that are not internalized but instead borne by parties not directly involved in the market interaction. Calls to show social responsibility for these third parties have become more prominent in public and academic debates. ${ }^{1}$ Shleifer (2004), for instance, presents five stylized examples where market competition results in unethical behavior. In his view, competition, and not greed, forces firms to reduce costs. He argues that only the competitor with the lowest costs has good chances to stay in the market, which might tempt firms to even engage in unethical behavior. Shleifer mentions child labor as one way to reduce production costs. A similar example is corruption, i.e., a firm might reduce its expenses by bribing officials who can influence taxes and tariffs. More recently, political philosopher Michael J. Sandel (2012) argues that not only competition but also market participation by firms and consumers in itself influences behavior and thereby can erode social responsibility. Sandel argues that preferences may change due to market interaction, and different market designs might induce different socially responsible behavior. ${ }^{2}$ In this vein, Bartling and Weber (2013) posit that it is important to understand what factors are decisive: "Many things differ between individual choices and market decisions. These include diffusion of responsibility between market participants, the use of contextually rich terms like 'prices', 'profit', and 'selling' in market contexts, and strategic motives and opportunities for social learning that may be present in market interaction but absent in individual choice" (p. 29, italics added by the current authors). ${ }^{3}$

In this paper we investigate how different market characteristics might affect market interaction in the presence of negative externalities on others. Our experimental study disentangles different

\footnotetext{
${ }^{1}$ Apple Inc, for example, was blamed for cheap production and poor working conditions at supplier Foxconn (see, for example, Suicides at Foxconn: Light and death (2010)). Walmart is regularly criticized for low wages, poor working conditions and inadequate health care. A substantial cut in the workforce allows for prices of usually about 15 percent below competitors. However, this also leads to rather poor working conditions at the stores (see, for example, Clifford (2013)). Poor working conditions and bad health care are also often criticized in the primary sectors, where social responsibility becomes more relevant; see, for example, gold mining in Ghana (Yankson (2010)) or Government of Canada (2015), who announced a "strategy to advance social responsibility in Canada's extractive sectors abroad."

2 Besley (2013) discusses Sandel's (2012) "What Money Can’t Buy" from an economics perspective.

${ }^{3}$ Similarly Falk and Szech (2013) highlight the importance of three essential features of market interacton: "First, [...] responsibility and feelings of guilt may be shared and thus diminished. Second, market interaction reveals social information about prevailing norms. [...] Third, markets provide a strong framing and focus on materialistic aspects [...]"(p. 708).
} 
market characteristics and looks at the impact of each on the willingness to avoid negative externalities caused by market transactions. Following the suggestions of Bartling and Weber (2013), we consider three characteristics that may affect decisions in markets compared to individual decisions. First, in most markets at least two parties participate and thereby share responsibility for the outcomes. Hence, responsibility might be diffused relative to individual decisions. Dana et al. (2007), for example, provide evidence for diffusion of responsibility in a dictator game with two dictators. Bartling and Fischbacher (2012) find a similar result in a four-person dictator game where delegation can lead to diffusion of responsibility. Conrads et al. (2013) show that diffusion of responsibility encourages dishonest behavior in teams as opposed to in individual decisions. Second, markets often provide social information. Typically it is possible to observe the behavior of others in markets, for instance, if market participants observe others buying products that come with negative externalities on third parties. Lefebvre et al. (2014), for instance, provide evidence for erosion of moral values caused by social information. In their experiment, information about low compliance rates increases tax evasion. Similarly, in a market setting, social information might indicate a kind of social appropriateness of trading an "unethical" good. Third, markets usually entail a specific market framing, with terms such as "buyer," "seller," and "price." This may change the focus from moral considerations about potential adverse outcomes for third parties towards materialistic issues and negotiation or profit considerations. For example, Cohn et al. (2014) show that employees of a bank behave in a more profit-oriented way when a decision situation is put in a frame that reminds them of their business culture. To disentangle the effect of these three major market characteristics, we start with individual behavior as a baseline. Additional treatments add one market characteristic at a time, so that the last treatment exhibits all three characteristics. Our results show that the considered market characteristics actually influence behavior in opposing directions. Social information seems to increase socially responsible behavior. Diffusion of responsibility and in particular market framing tend to increase the willingness to accept the presence of negative externalities.

Our experimental study complements the research of Falk and Szech (2013), Bartling et al. (2015) and Kirchler et al. (2015) by disentangling different market characteristics that may influence socially responsible behavior. Similar to our study, they employ experiments where the market participants' behavior has an impact on third parties who are not involved in the market. An exchange of a low-cost product leads to the maximum gain for the trading parties, but this product is associated with negative externalities. Not trading this good reduces the subjects' gain but also eliminates the negative externalities. Falk and Szech (2013) and Bartling et al. (2015) provide evidence supporting Sandel's (2012) warnings in controlled environments. Subjects have a 
Table 1 Experimental Treatments and the Three Market Characteristics.

\begin{tabular}{lll}
\hline \hline Treatment & Decision Type & Added Market Characteristic \\
\hline INDIVIDUAL & individual decisions & baseline \\
GROUP & interdependent decisions & 1) diffusion of responsibility \\
GROUPINFO & $\begin{array}{l}\text { interdependent decisions } \\
\text { with social information }\end{array}$ & 2) social information \\
MFRAME & $\begin{array}{ll}\text { interdependent decisions } \\
\text { with social information }\end{array}$ & 3) market framing \\
& and market framing & \\
\hline
\end{tabular}

higher willingness to accept the presence of negative externalities in market interactions than in individual decisions. This raises the question which specific market characteristics are responsible for the differences in behavior. Kirchler et al. (2015) test whether different interventions to overcome adverse outcomes work differently in market interactions than in individual decisions. They find that reduced anonymity increases social responsibility in individual decisions to a larger extend than in market interactions. They speculate that this difference is due to diffusion of responsibility and social information that is available in market interaction but not in individual decisions. The focus of their study, however, is not to differentiate the effects of these two market characteristics.

\section{Experimental Design}

Differences between individual decisions and decisions in market interactions are likely to be driven not just by a single factor. As outlined above, our focal market characteristics are: 1) diffusion of responsibility, 2) social information, and 3) market framing. We separate the three market characteristics by designing four experimental treatments. We employ INDIVIDUAL as the baseline treatment. Table 1 highlights how each of the three market characteristics is incorporated through an additional treatment. In GROUP, the individual decisions are interdependent, which adds the characteristic of 1) diffusion of responsibility. GROUPINFO adds 2) social information. Finally, MFRAME incorporates a 3) market framing. MFRAME thus comprises all three considered market characteristics. Our design promises to provide clean insights into how each market characteristic influences socially responsible behavior.

In all experimental treatments, subjects have to choose between two potential outcomes resembling a trade or no trade decision. They select either an outcome with a gain for the subject and negative externalities for a third party (trade) or an outcome with no gain for the subject and no negative externalities for a third party (no trade). Thus, similar to the markets in Falk and Szech (2013), 
Table 2 Decision Situations.

\begin{tabular}{lcc}
\hline \hline & no trade & trade \\
\hline $\begin{array}{l}\text { in MFRAME } \\
\text { in other treatments }\end{array}$ & "not buy" or "not sell" & "Ouy" or "sell" \\
"Option L" & "Option R" \\
\hline situation 1 & no gain, no externalities & no gain, externalities \\
situation 2 & no gain, no externalities & 2.50 Euro each, externalities \\
situation 3 & no gain, no externalities & 5.00 Euro each, externalities \\
situation 4 & no gain, no externalities & 7.50 Euro each, externalities \\
situation 5 & no gain, no externalities & 10.00 Euro each, externalities \\
situation 6 & no gain, no externalities & 12.50 Euro each, externalities \\
situation 7 & no gain, no externalities & 15.00 Euro each, externalities \\
situation 8 & no gain, no externalities & 17.50 Euro each, externalities \\
situation 9 & no gain, no externalities & 20.00 Euro each, externalities \\
situation 10 & no gain, no externalities & 22.50 Euro each, externalities \\
situation 11 & no gain, no externalities & 25.00 Euro each, externalities \\
situation 12 & no gain, no externalities & 27.50 Euro each, externalities \\
situation 13 & no gain, no externalities & 30.00 Euro each, externalities \\
\hline
\end{tabular}

Bartling et al. (2015), Kirchler et al. (2015) and many other market interactions outside the lab, our decision tasks model situations in which people can sacrifice own gains from trade to avoid negative consequences for third parties. To keep the setting simple, we abstract from a sophisticated market structure and focus on bilateral exchange decision tasks with exogenously set prices. As emphasized by Breyer and Weimann (2014), such stylized exchange decision tasks closely resemble decisions in many market interactions, such as buying a particular product in a shop. In these market interactions, prices are fixed in the short-run, and buyers and sellers do not directly engage in bargaining. Kirchler et al. (2015) employ similar tasks and argue "we believe that this . . . decision making . . resembles many everyday life situations of decisions in market settings" (p. 22) where customers "decide about buying or not buying a product (often at varying prices), and in case of buying it they are obviously willing to accept the potential harm done to uninvolved third parties" (p.22).

\subsection{Decision Situations}

Subjects are randomly assigned to a role, either A or B. One subject in role A is randomly matched with one subject in role B. They represent a buyer and a seller. The matching is fixed for the whole experiment. One group, consisting of a buyer and a seller, determines the outcomes for these two subjects and for a third uninvolved party. Each group is not only asked to make a single decision between trade and no trade. Instead, every treatment employs the same list with 13 situations, as shown in table 2. Only the surplus for the two subjects changes between the 13 situations. We vary the potential gains from a trade since subjects are likely to have different threshold values of gains for which they accept the negative externalities. The buyer and the seller 
gain the same amount of money in every situation. ${ }^{4}$

Subjects are presented with the 13 situations shown in table 2 in ascending order, starting with situation 1. The potential individual gains increase in 2.50-Euro-steps, from 0.00 Euro in situation 1 to 30.00 Euro in situation 13. From the instructions, subjects know in advance which decisions will follow. At the end of the experiment, one situation is randomly selected and the chosen outcome implemented. When subjects opt for no trade, the negative externalities are avoided and subjects receive no gain. When trade is realized, the group receives the specific gain of that decision situation and the negative externalities occur. The potential negative externalities are kept constant across all decision situations.

\subsection{Implementation of Negative Externalities}

Negative externalities are characterised by the fact that a party that is not involved in the transaction has to bear adverse consequences. In markets, this party is often distant from the parties making the decision. To assure higher external validity, we chose to impose the negative externalities on a third party who is remote from the subject pool: One needy child in a different city did not receive a warm meal on one day.

We implemented the negative externalities as follows. In Germany, pupils of many schools receive a lunch at their school, typically provided by an independent catering company. Lunches are generally paid for by children's parents. In addition, charities sponsor warm meals for children who are "not sufficiently fed at home" (Düsseldorfer Tafel (2013)). The charities take the donated money to buy warm meals from the school's caterer. We selected one of these charities that provide lunches for children living in a different city. ${ }^{5}$ First, we assign one meal to each group of subjects in our experiment. As default, we donate 124 meals to the charity, one for each of the 124 groups. These meals are provided to children who would otherwise not receive a warm meal. However, if a group trades, subjects accept the negative externalities, and we subtract one warm meal from the default. Hence, the charity can only buy one fewer meal from the caterer. So for each group that accepts the negative externalities, a child cannot receive its warm meal at the school. ${ }^{6}$ Some

\footnotetext{
${ }^{4}$ This design choice is intended to reduce the impact of factors other than the three market characteristics on behavior, such as fairness considerations. Bartling et al. (2015) indeed find that buyers - in their particular setting - do not use their dominant position and do not exploit sellers but instead share surplus from a trade almost equally.

${ }^{5}$ The Kindertafel Düsseldorf charity (see Düsseldorfer Tafel (2013)).

${ }^{6}$ Overall, our experiment increased the well-being of some poor children. No child was actually harmed but only relative to our default. The consequence for the child - no warm meal on one day - is probably more dramatic than the reduction in payoff for another subject by Bartling et al. (2015). Whether it is more or less dramatic than killing a mouse as in Falk and Szech (2013) or reducing measles vaccination as in Kirchler et al. (2015) is debatable. Arguably, it might be efficient to trade and accept the negative externalities, donate a part of the gains from trade to the charity to reduce the negative externalities and keep the remainder. However, our experimental design makes it unlikely that
} 
subjects could have questioned whether we really implemented the consequence of not providing a warm meal. To overcome this issue, we heavily stressed that the Cologne Laboratory for Economic Research always guarantees the truth of all statements in the instructions. ${ }^{7}$ In a post experimental debriefing, subjects were informed that money will be donated to a charity and that this donation is reduced if subjects accepted the negative externalities. We allowed the subjects to verify our payments to the charity after the experiment. It is therefore very likely that the subjects believed that negative externalities were realized.

\subsection{The Market Characteristics}

Individual decision as baseline

In each treatment, two subjects are randomly assigned to a group. This group may trade and accept the negative externalities. Participant $\mathrm{A}$ is dictator-like in INDIVIDUAL, as shown in table 3. To keep the INDIVIDUAL treatment as similar as possible to the other treatments, both participants $\mathrm{A}$ and $\mathrm{B}$ make the 13 decisions, but only participant A's decision determines the outcomes. ${ }^{8}$ For example, when situation 3 is selected and participant A chooses trade in this situation, trade is realized. In this case, participant A and participant B receive 5.00 Euro each, and a child receives no warm meal on one day. However, when participant A chooses no trade, no trade is realized. Both participants then receive no gain, but the child receives a warm meal. Consequently, participant A bears the entire responsibility and participant B's choice is irrelevant. The child remains passive in all treatments. We take the decisions of participant A to measure individual behavior as a baseline. The decisions of participant B do not have any consequences. As in all other treatments, subjects simultaneously make their decisions for each situation.

\section{Interdependent Decisions}

GROUP is identical to INDIVIDUAL except that the outcome depends on the decisions of both participants $\mathrm{A}$ and $\mathrm{B}$, as shown in table 4. Only if participants $\mathrm{A}$ and $\mathrm{B}$ both choose trade, the outcome comprises gains for participants and negative externalities. Whenever at least one participant opts for no trade, the outcome is no gain for the participants and no externalities. This resembles a market interaction in the sense that when at least one party - buyer or seller - refuses,

the subjects could follow this reasoning because subjects were only informed ex ante about the consequences of their decisions and not about how the consequences were implemented in detail. We did not explain the donation procedure in detail in order to focus on the effect of market characteristics on socially responsible behavior.

${ }^{7}$ This code of conduct is also well known by all subjects of the subject pool.

${ }^{8}$ Including the outcomes for the (non-decisive) participant B. As in the other treatments, participant B is also modelled in INDIVIDUAL to control for other factors like, for example, other-regarding preferences. 
Table 3 Payoff matrix for one decision situation in the treatment INDIVIDUAL.

Role B

\begin{tabular}{ll|l|l|}
\multicolumn{1}{c}{ no trade } & \multicolumn{1}{c|}{ trade } \\
\cline { 3 - 4 } Role A & no trade & Role A: no gain & Role A: no gain \\
& & Role B: no gain & Role B: no gain \\
& Child: warm meal & Child: warm meal \\
\cline { 3 - 4 } & trade & Role A: $x$ Euro & Role A: $x$ Euro \\
& Role B: $x$ Euro & Role B: $x$ Euro \\
& Child: no warm meal & Child: no warm meal \\
\cline { 3 - 4 } & &
\end{tabular}

Table 4 Payoff matrix for one decision situation in the treatments GROUP, GROUPINFO, and MFRAME. Role B

\begin{tabular}{|c|c|c|c|}
\hline \multirow{7}{*}{ Role A } & & \multicolumn{2}{|l|}{ no trade } \\
\hline & & Role A: no gain & Role A: no gain \\
\hline & no trade & Role B: no gain & Role B: no gain \\
\hline & & Child: warm meal & Child: warm meal \\
\hline & & Role A: no gain & Role A: $x$ Euro \\
\hline & trade & Role B: no gain & Role B: $x$ Euro \\
\hline & & Child: warm meal & Child: no warm meal \\
\hline
\end{tabular}

trade cannot occur. Thus only if both parties agree on trade, the gains and negative externalities can be realized. While only participant $\mathrm{A}$ is responsible for the outcomes of the three parties in INDIVIDUAL, responsibility is diffused in GROUP.

\section{Interdependent Decisions with Social Information}

Except for the instructions, there is no information provided in INDIVIDUAL and in GROUP. Decisions are interdependent in GROUP, but participants cannot influence each other as they never are informed about what the other party did. In contrast, subjects receive social information in GROUPINFO. In addition to GROUP, subjects also see the other participant's choice of the preceding situation in GROUPINFO. Subjects simultaneously make their decisions for situation one. Then they reach the next stage, situation two. While participant A and participant B again make their decisions simultaneously for situation two, they see the other participant's choice for situation one. After both have made their decision for situation two, they reach the next stage. Both see the other's decision for situation two, and simultaneously make the decision for situation three. This procedure continues until the last stage, situation 13.

\section{Interdependent Decisions with Social Information and Market Framing}

MFRAME is equivalent to GROUPINFO except for the wording. In all treatments described so far, role A and role B were neutrally called "participant A" and "participant B", who both "made decisions." In MFRAME, role A is called "buyer" and role B is called "seller." Only if both parties agree to trade, i.e., opt for "buy" and "sell", respectively can the "trade" take place at a given 
"price." The seller's gain is the price paid by the buyer. The buyer's gain is the buyer's valuation less the price paid. The price is fixed for each decision situation, and parties can only decide whether to trade or not at the quoted price. If a trade takes place, the buyer receives an additional amount of money resembling the valuation of the purchased good. The buyer pays the price to the seller. The buyer's valuation and the price are set such that the gains for buyer and seller are the same as in the other treatments. The price increases in 2.50-Euro-steps, from 0.00 Euro in situation 1 to 30.00 Euro in situation 13. The buyer's valuation increases in 5.00-Euro-steps, from 0.00 Euro in situation 1 to 60.00 Euro in situation 13. Thus, the seller's gain (price less costs) equals the buyer's gain (valuation less price) in all decision situations. ${ }^{9}$

\subsection{Hypotheses}

A purely self-interested rational agent prefers own gain over no gain, or trade over no trade in all decision situations. ${ }^{10}$ Hence, under standard economic assumptions, it is predicted that behavior is the same in all treatments. Subjects always choose trade and always accept the presence of negative externalities.

Null hypothesis: All subjects choose trade in all decisions of all treatments, i.e., the number of subjects avoiding the negative externalities is the same in all treatments.

Alternatively, subjects might have a willingness to forego their own gain to avoid negative externalities on a third party. They may, for example, have social preferences ${ }^{11}$ and choose no trade rather than trade. Subjects might, however, not only consider the well-being of a third party in general. They could be influenced differently by the existing market characteristics. Further, there could even be subjects with a strict ethical code of conduct dictating that negative externalities are never acceptable. We call these kind of subjects steadfast because they stick to their code of conduct. They avoid negative externalities by choosing no trade in every situation, even when they could receive 30.00 Euro from trade. We take the number of steadfast subjects as a second measure on socially responsible behavior. ${ }^{12}$

\footnotetext{
${ }^{9}$ For simplicity and to keep the setting comparable to the other treatments, we normalized production costs to zero. For example, in decision situation 3, the price is 5.00 Euro and the buyer's valuation is 10.00 Euro. So - as in the other treatments - role A and role B receive a gain of 5.00 Euro each when both choose trade.

10 The agent is indifferent in situation 1.

${ }^{11}$ For example, as outlined in the Appendix of Bartling et al. (2015). They present a standard model of social preferences (Fehr and Schmidt (1999)), modified so that it also incorporates the uninvolved third party.

${ }^{12}$ Strictly speaking, we cannot differentiate between subjects with a strict ethical code of conduct, i.e., subjects who would never choose trade and those who did not choose trade in our experiment but would choose trade for potential gains higher than 30.00 Euro.
} 


\section{1) Diffusion of responsibility}

Subjects may face a cost of accepting the presence of negative externalities. When two subjects in a group, rather than one individual, bear responsibility for the outcomes, they might feel like sharing this cost. As a consequence, they might be willing to tolerate negative externalities in a group to a larger degree than an individual. In this case, diffusion of responsibility should lead to a lower willingness to select no trade and avoid negative externalities. ${ }^{13}$ Similarly, diffusion of responsibility might also erode the steadfastness of subjects because allowing for the negative externalities might appear somewhat more socially acceptable if another person also agrees.

Alternative hypothesis 1 (diffusion of responsibility): Fewer subjects avoid the negative externalities and fewer subjects are steadfast in GROUP than in INDIVIDUAL.

\section{2) Social information}

There is no clear hypothesis on how social information affects behavior. Lefebvre et al. (2014) show that providing information about low tax compliance rates increases tax evasion. Similarly, social information might increase the willingness to trade in our experiment. For instance, subjects with a tendency to avoid negative externalities could be inclined to choose trade for lower potential gains after observing the other subject selecting trade. Accepting the negative externalities might be perceived as being more socially acceptable after observing that the other subject chose trade in the previous situation.

Alternative hypothesis 2a (social information): Fewer subjects avoid the negative externalities and fewer subjects are steadfast in GROUPINFO than in GROUP.

However, two explanations underpin the opposite conjecture, i.e., that social information increases the willingness to avoid trade. A first potential explanation is that observing the other

${ }^{13}$ For example, Dana et al. (2007), Bartling and Fischbacher (2012) and Conrads et al. (2013) provide experimental evidence for diffusion of responsibility. Dana et al. (2007) employ a dictator game as the baseline: The dictator can choose between a "fair" allocation or an allocation where the dictator receives a higher payoff at the cost of the other party. They add a second dictator in one treatment variation. Similar to our experiment, the two dictators get the maximum gain and the third party is harmed only if both dictators choose this option. Otherwise the dictators receive the lower "fair" payoff and the third party is not harmed. Dana et al. (2007) find a significant decrease in the "fair" allocations caused by diffusion of responsibility (from 74 to 35 percent). Bartling and Fischbacher (2012) find a similar result in a four-person dictator game. In a baseline treatment, a principal A can choose a "fair" allocation. A can also choose an allocation that maximizes payoffs for $\mathrm{A}$ and for his agent $\mathrm{B}$ at the cost of two receivers C. As one treatment variation, A can share responsibility by delegating this decision to B. Diffusion of responsibility, through delegation, decreases the share of "fair" allocations in Bartling and Fischbacher (2012) (from 35 to 20 percent). Conrads et al. (2013) provide evidence that diffusion of responsibility is likely to lead to more dishonest behavior in a simple coin flip task. Subjects report an average production of 3.86 in a team but only 3.31 individually (In fact, true production is randomly determined with an expected value of 2.50 .). 
subject selecting no trade and thereby avoiding the negative externalities might convince subjects with an opposing inclination to choose no trade as well. A subject may not want to be the first one who behaves ethically objectionable and would rather wait for the other one to switch first. A second potential explanation for higher social responsibility caused by social information follows a different reasoning. After observing that the other subject already selected trade in the previous situation, it is reasonable to expect that this subject also chooses trade for a higher potential gain in the next situation. When one subject expects that the other one will choose trade, the subject's decision becomes decisive, and thereby the decision situation is very similar to the dictator-like decision in INDIVIDUAL. The subject who chose no trade in the previous situation might then feel obliged to continue to choose no trade to avoid the negative externalities.

Alternative hypothesis 2b (social information): More subjects avoid the negative externalities and more subjects are steadfast in GROUPINFO than in GROUP.

It may also be possible that the different effects of social information, described by the hypotheses $2 \mathrm{a}$ and $2 \mathrm{~b}$, cancel out.

\section{3) Market framing}

Tversky and Kahneman (1981), Tversky and Kahneman (1986) and Kahneman (2003) have already shown that the framing of a decision may change behavior in markets. Markets usually entail a specific market framing, with terms such as "buyer," "seller," and "price." Cohn et al. (2014) provide evidence that employees of a bank behave more profit-oriented when they are focused on their business culture. They show that bankers do not behave more dishonestly than other employees in general. However, when their specific professional identity is rendered salient, behavior shifts towards norms associated with this identity. The focus on professional banking seems to be associated with profit-orientation and dishonesty. Similarly, it is sensible to conjecture that not markets in general but the specific framing of a market in particular induces a behavior associated with this framing. Market framing may change the focus from moral considerations about potential adverse outcomes for third parties towards materialistic issues, negotiation or profit considerations. This may decrease the willingness to avoid negative externalities. It also could decrease the share of subjects behaving steadfastly.

Alternative hypothesis 3 (market framing): Fewer subjects avoid the negative externalities and fewer subjects are steadfast in MFRAME than in GROUPINFO. 


\subsection{General Procedures}

The experiment was conducted in the Cologne Laboratory for Economic Research, a computer lab of the University of Cologne. 248 subjects, primarily students of the University of Cologne, were recruited via ORSEE (Greiner (2015)) from the lab's subject pool. Each subject took part in only one treatment and was randomly assigned to one of the roles, A or B, in one group consisting of two subjects.

Subjects received written instructions and were asked to correctly answer comprehension questions before the experiment could start. The experimenter read a summary of the instructions aloud to ensure common information. To reduce the influence of other factors on delicate moral decisions, the experiment was computerized with z-Tree (Fischbacher (2007)), and we implemented a double-blind payment procedure. Subjects drew a card to be allocated to a specific computer terminal. Later, each subject received a voucher code. At the end of the experiment, subjects were asked to go to another building. There, they separately entered a room. A person with no knowledge of the experiment handed over the earnings in a sealed envelope in exchange for the voucher code.

Experimental sessions took place from October 1-4, 2013 and lasted between 60 and 90 minutes. Subjects received a flat payment of 2.50 Euro (1.00 Euro $=1.35$ US-Dollar at the time of experiment) for attending and could earn an additional amount of between 0.00 Euro up to 30.00 Euro, depending on behavior. 32 subjects formed 16 groups in each experimental session. ${ }^{14} \mathrm{We}$ selected the same meal on the charity's website 16 times during the experiment. We then received a list from the charity with the names of 16 children to confirm our donation (see Appendix). We assigned one child from the list to one group in the experimental session. Before we confirmed the donation to the charity, we checked the behavior of each group. When the group accepted the negative externalities for the implemented decision, we subtracted the corresponding child from the charity's list and donated an amount of money corresponding to the updated list. In our experiment, 124 groups donated 49 meals, each worth 5.20 Euro, for a total donation of 254.80 Euro. Subjects' average earnings were 12.16 Euro.

\section{Results}

As potential gains increase with every situation, subjects may choose no trade for the first situations, switch to trade at some point, and choose trade thereafter. We define the switching point as the number of the decision situation where a subject chooses trade for the first time. The minimum willingness to accept (MWTA) is defined as the monetary value at this switching point,

\footnotetext{
${ }^{14}$ In the last session, only 24 subjects showed up, forming 12 groups.
} 


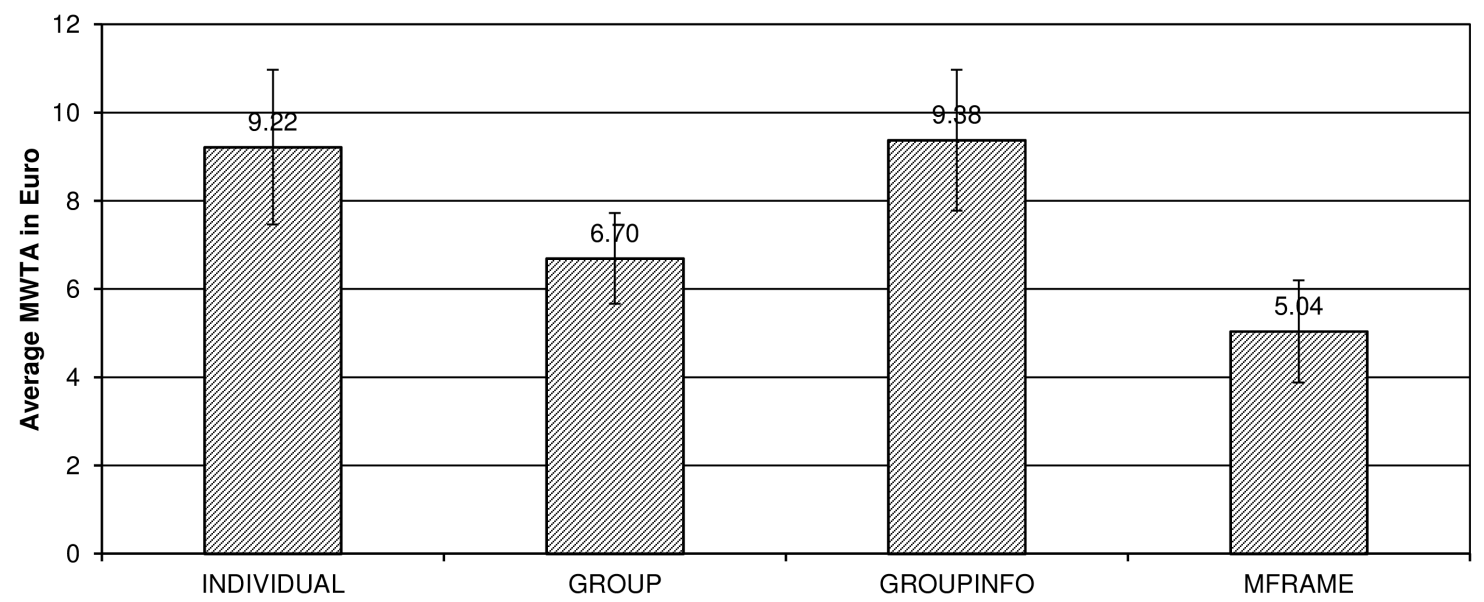

Figure 1 Average Minimum Willingness to Accept (MWTA) in Euro (+/- standard deviation).
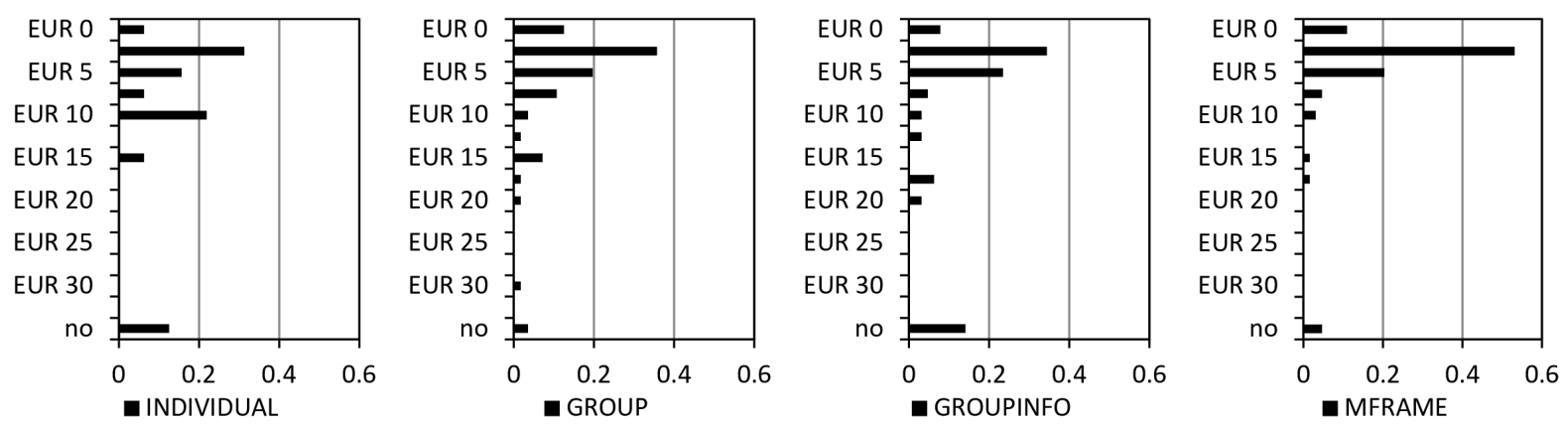

Figure 2 Minimum Willingness to Accept (MWTA) Histograms.

i.e., the potential gains that a subject receives at the switching point. ${ }^{15}$ It is the minimum amount of money that a subject requires to accept the negative externalities. A purely self-interested rational subject has the lowest MWTA, ranging from 0.00 Euro to 2.50 Euro. A steadfast subject, by definition, has no unambiguous MWTA. We assume a MWTA of 32.50 Euro in those cases in order to be able to report an average MWTA for each treatment. ${ }^{16}$ An increase in MWTA or an increase in steadfastness can be interpreted as indicators of an increase in socially responsible behavior.

The average MWTA is 9.22 Euro in INDIVIDUAL (see Figure 1). When the potential gain is about twice as high as the costs of the warm meal, subjects start preferring trade over no

${ }^{15}$ For simplicity we determined the MWTA of a subject as his potential earnings from the first switch from no trade to trade. Thus, to determine the MWTA of a subject, we ignore the rare cases in which a subject switched back from trade to no trade and maybe switched again at a later situation.

${ }^{16}$ As steadfast subjects never accept negative externalities, we cannot identify an unambiguous minimum amount of money that they request in order to accept negative externalities. Steadfast subjects refuse to choose trade in every situation, including situation 13 with potential gains of 30.00 Euro. Suppose there would have been a situation 14 . This situation would have had a potential gain of 32.50 Euro. The steadfast subjects might have switched from no trade to trade at this point. This would imply a MWTA of 32.50 Euro. In this sense a MWTA of 32.50 Euro is a conservative assumption for steadfast subjects. 
trade in INDIVIDUAL. On average, subjects switch to trade just before situation 5. Figure 2 shows histograms of the MWTA of all subjects for each treatment. ${ }^{17}$ The high average MWTA in INDIVIDUAL is driven by a substantial fraction of subjects with a MWTA of 10.00 Euro and by a considerable proportion of subjects who refuse to choose trade in any situation. 12.5 percent are steadfast and choose no trade in every situation in INDIVIDUAL, i.e., for all potential gains from 0.00 Euro up to 30.00 Euro. We asked those subjects who never accept the negative externalities whether they would prefer trade over no trade when we would pay 100.00 Euro. All subjects refused this in INDIVIDUAL. We further asked whether we could offer any amount of money to convince subjects to trade and to accept the negative externalities. These 12.5 percent of subjects also refused any amount of money. ${ }^{18}$ This might indicate that there is a substantial share of subjects who follows a strict ethical code of conduct. Negative externalities seem to be unacceptable for them.

\subsection{Diffusion of responsibility}

Subjects are less concerned about third parties in GROUP than in the individual benchmark. When decisions are interdependent and subjects share responsibility (GROUP), the minimum amount of money that subjects request to accept the negative externalities is about 27 percent lower than in INDIVIDUAL. Diffusion of responsibility decreases the MWTA to 6.70 Euro (see figure 1). About 50 percent of the subjects already prefer trade when the potential gain is 2.50 Euro or lower in GROUP. A large majority of more than two thirds accepts the negative externalities no later than in situation 3, for a potential gain of 5.00 Euro or less (see figure 2).

The average MWTA and the histograms give an overview on how the considered market characteristics change socially responsible behavior. Regression analyses complement the results by providing additional statistical insights. Table 5 presents random-effects ordered probit models to understand the impact of the different market characteristics. The dependent variable, no trade, can be interpreted as a willingness to avoid the negative externalities. In INDIVIDUAL and GROUP, the dependent variable takes integer values because each subject's decisions are independent, and subjects either choose no trade or trade in every decision situation. In GROUPINFO and in MFRAME, the two group members' averages of the two decisions are the independent observations because subjects observe the behavior of their other group member. The

17 The histograms show the MWTA of each individual, even though the two MWTAs of a group are not statistically independent in GROUPINFO and in MFRAME. Our statistical tests take into account dependence of individuals' decisions, i.e., in GROUPINFO and in MFRAME, when information about the other's choices might affect behavior, we take the group's average decision.

${ }^{18}$ Of course these two questions were purely hypothetical and not incentivized. 
dependent variable then takes the value 0.5 if one subject chooses no trade and the other subject chooses trade in a particular decision situation. The three market characteristics are dummy variables in the regression models. For instance, 3) market framing takes the value 1 only in the treatment MFRAME. However, 2) social information takes value 1 not only in the treatment GROUPINFO but also in the treatment MFRAME because this treatment also includes social information. This partly explains why coefficients of the market characteristics do not perfectly match the changes observed when comparing the respective MWTAs (compare figure 1 and table 5). ${ }^{19}$ 'Potential gains' takes values from 0.00 (Euro) to 30.00 (Euro), each corresponding to a particular decision situation. For example, in situation 1, the potential gain is 0.00 Euro, and it increases in 2.50-Euro-steps to 30.00 Euro in situation 13 (see table 2).

The MWTA is lower in GROUP than in INDIVIDUAL (see table $5 ; p=0.0793$, Mann-Whitney U test, one-sided). Interestingly, 12.5 percent of the subjects are steadfast in INDIVIDUAL, but only 3.6 percent never choose trade in GROUP (see figure 2). This seems to indicate that diffusion of responsibility reduces steadfastness ( $p=0.056$, Mann-Whitney U test, one-sided). Table 6 presents an ordered probit regression model with steadfastness as the dependent variable. ${ }^{20}$ The decrease in steadfastness caused by diffusion of responsibility barely misses significance $(p=0.1000)$.

\section{Result 1:}

Diffusion of responsibility weakly significantly decreases the willingness to avoid negative externalities and subjects' steadfastness.

\subsection{Social Information}

There is no clear hypothesis on how social information affects behavior. It may be that social information decreases the willingness to avoid negative externalities (alternative hypothesis 2a), but social information also may increase the willingness to choose no trade (alternative hypothesis $2 \mathrm{~b})$. Our data rejects alternative hypothesis $2 \mathrm{a}$ in favor for alternative hypothesis $2 \mathrm{~b}$, i.e., social

\footnotetext{
${ }^{19}$ Regression models make use of more data than our non-parametric tests for two reasons. First, regression models include data from all four treatments, whereas non-parametric tests only compare data from two treatments. For example, when understanding the effect of social information on no trade, our non-parametric tests compare only two treatments (GROUP, GROUPINFO). Regression models include all data, two treatments without social information (INDIVIDUAL, GROUP) and two treatments with social information (GROUPINFO, MFRAME). Second, regression models capture every single decision between no trade and trade and consider the panel data characteristics, while nonparametric tests lose information by aggregating the decisions into one variable, MWTA. Thus, the non-parametric tests may also ignore inconsistent choices.

${ }^{20}$ Steadfastness takes the value 1 only if the subject chooses no trade in all of the 13 decision situations. Otherwise it takes the value 0 . When the average group decision is the independent observation (in GROUPINFO, in MFRAME), then steadfastness only takes the value 1 if both group members behave steadfastly. When one subject behaves steadfastly, the steadfastness takes the value 0.5. The market characteristics are dummy variables, as in the regression models of table 5 described above.
} 
Table 5 Regression Analyses: No Trade Choice on the Three Market Characteristics and Potential Gains.

\begin{tabular}{l|cc}
\hline \hline Dependent Variable & \multicolumn{2}{|c}{ No trade } \\
Regression Model & Random-effects & Ordered Probit \\
& $(1)$ & $(2)$ \\
\hline 1) Diffusion of responsibility & -0.204 & -0.320 \\
& $(0.216)$ & $(0.345)$ \\
2) Social information & $0.508^{* *}$ & $0.667^{* *}$ \\
& $(0.211)$ & $(0.338)$ \\
3) Market framing & $-0.529^{* *}$ & $-0.892^{* *}$ \\
& $(0.236)$ & $(0.379)$ \\
Potentail gains & & $-0.123^{* * *}$ \\
& & $(0.006)$ \\
\hline Observations & 2040 & 2040 \\
\hline
\end{tabular}

Standard errors in parentheses; ${ }^{* * *} p<0.01,{ }^{* *} p<0.05,{ }^{*} p<0.10$.

Dependent variable, no trade, is ordinal: 1 if the decision is no trade in a particular situation and 0 of the decision is trade. If one subject chooses no trade and the other chooses trade, the dependent variable takes the value 0.5 in GROUPINFO and in MFRAME. The three market characteristics are dummy variables. 1) Diffusion of responsibility takes the value 1 if the treatment is GROUP, GROUPINFO, or MFRAME. 2) Social information takes the value 1 if the treatment is GROUPINFO, or MFRAME. 3) Market framing takes the value 1 if the treatment is MFRAME. 'Potential gains' controls for the size of potential gains from a trade. In decision situation 1, 'potential gains' takes the value 0.00 (Euro); it takes the value 2.50 (Euro) in decision situation 2. The maximum value of 30.00 (Euro) is associated with the decision in situation 13. The total number of observations consists of 32 subjects in INDIVIDUAL, 56 subjects in GROUP, 32 groups in GROUPINFO, and 32 groups in MFRAME, with 13 decisions each. Note, in the first stage, the decisions of the 64 subjects in GROUPINFO and the 64 subjects in MFRAME are independent, leading to 2040 observations in total.

Table 6 Regression Analysis: Steadfastness on the Three Market Characteristics and Decision Situation.

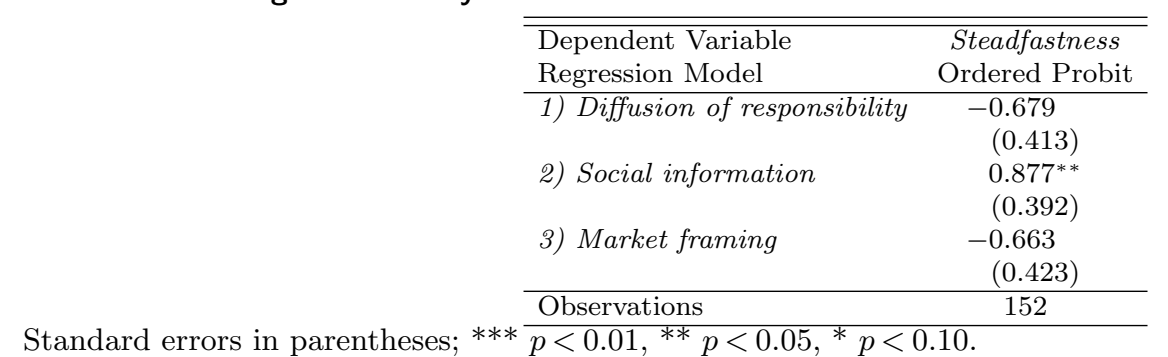

Dependent variable steadfastness is ordinal: 1 if the subject (or group) chooses no trade in every decision situation and 0 if the subject (both subjects of the group) chooses trade in any of the 13 decision situations. Otherwise, if one of the two subjects chooses no trade in every of the 13 decision situations, the dependent variable takes the value 0.5 in GROUPINFO and in MFRAME. The three market characteristics are dummy variables. 1) Diffusion of responsibility takes the value 1 in the treatments GROUP, GROUPINFO, and MFRAME. 2) Social information takes the value 1 in the treatments GROUPINFO, and MFRAME. 3) Market framing takes the value 1 in the treatment MFRAME. The total number of observations consists of 32 subjects in INDIVIDUAL, 56 subjects in GROUP, 32 groups in GROUPINFO, and 32 groups in MFRAME, each with one degree of steadfastness.

information has a positive impact on social responsibility. The minimum amount of money subjects request for accepting the negative externalities increases substantially after adding social information. MWTA increases from 6.70 Euro to 9.38 Euro with social information (see figure 1). The histograms in figure 2 give a more detailed insight. About 80 percent accept the negative 
externalities for 7.50 Euro or less in GROUP, whereas only about 70 percent do the same in GROUPINFO. For higher stakes, the difference is even stronger. Less than 10 percent do not accept the negative externalities for 15.00 Euro or less in GROUP. However, about 25 percent do not accept the negative externalities for 15.00 Euro or less in GROUPINFO.

The positive effect of social information on the willingness to avoid negative externalities is statistically significant (see table $5 ; p=0.0767$, Mann-Whitney U test, two-sided). 14.1 percent of the independent observations are steadfast and choose no trade in every of the 13 decision situations in GROUPINFO (see figure 2). ${ }^{21}$ However, only 3.6 percent behave steadfastly in GROUP (see table $6 ; p=0.0087$, Mann-Whitney U test, two-sided).

\section{Result 2.1:}

Social information increases the willingness to avoid negative externalities. It also increases the steadfastness.

We can think of at least three distinct ways of how social information influences social responsibility. To illustrate differences between treatments with respect to these three behavioral patterns (called X, Y, Z in the following), we classify the groups in GROUPINFO and in MFRAME, as shown in table 7 . In a fourth pattern, subjects seem to be less affected by social information because they switch from no trade to trade in exactly the same decision situation (type S). ${ }^{22}$ Although there is no social information in GROUP, i.e., subjects cannot condition their switching behavior on the observed behavior of the other subject, for comparative reasons we also classify the groups in GROUP. Table 8 provides an overview about the average MWTA of each type of group in GROUP, GROUPINFO, and MFRAME. Further, table 8 shows the share of groups that belong to each type.

First, though it was rejected, there is some support for alternative hypothesis 2a on the individual level, i.e, observing the other subject choosing trade might convince subjects to behave less socially responsible. A purely self-interested subject chooses trade for the first time in decision situation 1 or 2 for a potential gain of 0.00 or 2.50 Euro, respectively. A subject who is convinced by this behavior should follow immediately after observing trade, i.e., in the next situation (type

${ }^{21}$ The steadfastness of groups with information takes the value 1 if both group members never choose trade. It takes the value 0 if both group members are not steadfast, i.e., both choose trade at least once. When one subject is steadfast, the group's steadfastness takes the value 0.5. There are 32 independent groups in GROUPINFO. Two of them have a degree of steadfastness of $1.0 ; 5$ of them show the value 0.5 . On average, about 14.1 percent of the groups are steadfast. The steadfastness does not differ between INDIVIDUAL and GROUPINFO $(p=0.4370$, Mann-Whitney U test, two-sided).

${ }^{22}$ A group is type $\mathrm{S}$ if both subjects switch to trade in the same decision situation (see table 7 ). 
Table 7 Classification of groups in the treatments with information (GROUPINFO and MFRAME).

The other subject switches

The subject immediately in the next

who switches first is purely self-interested situation

\begin{tabular}{lll|c|} 
& \multicolumn{2}{c}{ Yes } & No \\
\cline { 2 - 3 } & Yes & Type X & Type \\
\cline { 3 - 4 } & Nype Y & $Z$ \\
\cline { 3 - 4 } & & &
\end{tabular}

Additionally, we classify groups as type $\mathrm{S}$ when both subjects switch in exactly the same decision situation.

Table 8 Average MWTA of each type of group and the share of groups that belong to each type in GROUP, GROUPINFO, and MFRAME.

\begin{tabular}{|c|c|c|c|c|c|c|}
\hline \multirow[b]{2}{*}{ Type } & \multicolumn{2}{|c|}{$\overline{\text { GROUP }}$} & \multicolumn{2}{|c|}{$\overline{\text { GROUPINFO }}$} & \multicolumn{2}{|c|}{ MFRAME } \\
\hline & Share & MWTA & Share & MWTA & Share & MWTA \\
\hline S & 14.3 & 3.75 & 9.4 & 3.33 & 37.5 & 2.71 \\
\hline $\mathrm{X}$ & 21.4 & 2. & 40.6 & 3.17 & 31.3 & 2.75 \\
\hline Y & 3.0 & 6 & 9.4 & 24.58 & 9.4 & 15.00 \\
\hline $\mathrm{Z}$ & 60.7 & 9.04 & 40.6 & 13.46 & 21.9 & 8.04 \\
\hline$\overline{\Gamma o t a}$ & 100.0 & 6.70 & 100.0 & 9.38 & $\overline{100.0}$ & 5.04 \\
\hline
\end{tabular}

$\mathrm{X}) .{ }^{23}$ The share of type $\mathrm{X}$ groups increases from 21.4 percent in GROUP $^{24}$ to 40.6 percent in GROUPINFO ( $p=0.0961$, Mann-Whitney U test, two-sided). It indicates that social information seems to convince some subjects to behave less socially responsible. However, this effect barely decreases the treatment's MWTA. While the share of type X groups increases from GROUP to GROUPINFO, on average, type $\mathrm{X}$ groups behave more socially responsibly in GROUPINFO than in GROUP. In fact, the MWTA of type X groups in GROUPINFO is higher than the MWTA of type $\mathrm{X}$ groups in GROUP (3.17 vs 2.08, $p=0.0544$, Mann-Whitney $\mathrm{U}$ test, two-sided, $n=25$ ).

Groups of type $\mathrm{Y}$ and type $\mathrm{Z}$ both support alternative hypothesis $2 \mathrm{~b}$. The reasoning explaining type Y's behavior follows a similar notion to the reasoning for type X, i.e., observing a particular behavior might convince subjects to behave similarly. However, here the behavior goes in the opposing direction: If one subject chooses no trade, the other subject might behave socially responsibly too (type Y). ${ }^{25}$ Further, no subject might want to be the first in his group who switches to trade. We would expect to observe groups where both subjects are steadfast. This

${ }^{23}$ A group is type $\mathrm{X}$ if the following two conditions hold (see table 7). First, at least one subject switches to trade for 0.00 or 2.50 Euro (i.e., at least one subject is purely self-interested). Second, the other subject switches to trade immediately in the situation after observing the first subject switching to trade (i.e., the other subject follows the example of the first subject).

${ }^{24}$ Such a pattern can only emerge by chance in GROUP because subjects do not observe the behavior of others.

${ }^{25} \mathrm{~A}$ group is type $\mathrm{Y}$ if the following two conditions hold (see table 7). First, no subject switches to trade for 0.00 or 2.50 Euro (i.e., no subject is purely self-interested). Second, after observing the first subject switching to trade, the other subject switches to trade immediately in the next situation (i.e., the other subject follows the example of the first subject). In the beginning both subjects seem to wait for the other subject to switch first. As soon as one subject switches the other subject follows immediately. As a border case, we include groups in type Y if both subjects are steadfast, i.e., both subjects seem to wait for the other one. 
pattern exists but only rarely. Both subjects of a group are steadfast in about 6.3 percent of the groups in GROUPINFO, and no group shows this pattern in GROUP. Interestingly, the type $\mathrm{Y}$ groups show different behavior in GROUPINFO than in GROUP, primarily driven by the steadfast groups. For type Y groups, MWTA increases from 6.25 Euro in GROUP to 24.58 Euro in GROUPINFO ( $p=0.0202$, Mann-Whitney U test, one-sided, $\mathrm{n}=10)$. The share of type $\mathrm{Y}$ groups does not significantly increase from GROUP to GROUPINFO ( $p=0.5030$, Mann-Whitney U test, two-sided). Type Y groups in GROUPINFO postpone switching to trade until potential gains are higher and thus increase socially responsible behavior relative to type Y groups in GROUP.

For type $\mathrm{Z}$ groups, suppose one of the two subjects switches from no trade to trade. In type $\mathrm{X}$ and type $\mathrm{Y}$ groups, the other subject follows immediately by switching in the next situation. However, in type $\mathrm{Z}$ groups, the other subject refuses to switch in the next situation and thereby refuses to follow immediately. ${ }^{26} \mathrm{~A}$ subject must expect that another subject who has already switched to trade will continue to choose trade in situations with higher potential gains. A subject who did not switch in the previous situation might then feel responsible for avoiding the negative externalities. Due to this perceived responsibility, the second subject, who did not yet switch, might postpone switching to trade until a situation that entails higher potential gains. If this reasoning is true, we expect to observe a substantially higher average MWTA in GROUPINFO than in GROUP, primarily driven by a higher difference between the MWTA of the two group members in GROUPINFO than in GROUP. We also expect that in some groups one subject switches to trade for a rather low potential gain, while the other subject might even remain steadfast. In fact, the average MWTA for type Z groups is significantly higher in GROUPINFO, at 13.46 Euro, than in GROUP, at 9.04 Euro ( $p=0.0118$, Mann-Whitney U test, one-sided, $n=47)$. The share of type $\mathrm{Z}$ groups does not significantly decrease from GROUP to GROUPINFO ( $p=0.1105$, Mann-Whitney $\mathrm{U}$ test, two-sided). In type $\mathrm{Z}$ groups, one subject postpones switching to trade until situations that correspond to higher potential gains, and many subjects even remain steadfast after observing trade. In GROUPINFO, the difference between the MWTAs of the two subjects of type $\mathrm{Z}$ groups is substantially greater at an average of 16.54 Euro than in GROUP at an average of 12.50 Euro ( $p=0.0448$, Mann-Whitney $\mathrm{U}$ test, one-sided, $n=30)$. In type $\mathrm{Z}$ groups, the subjects who avoided the negative externalities seem to stick to no trade for very high potential gains. In about 38.5 percent of type $\mathrm{Z}$ groups ( 5 out of 13 groups), one subject remains steadfast even after observing trade in GROUPINFO. In only 11.8 percent of type Z groups (2

${ }^{26}$ A group is type $\mathrm{Z}$ if the other subject does not switch immediately to trade in the next situation after observing the first subject switching to trade (see table 7), (i.e., the other subject does not immediately follow the example of the first subject). As a consequence, type Z groups show a difference between the MWTA of the two subjects of at least 5.00 Euro. This includes cases where a subject follows relatively soon but also cases where the second subject is steadfast and never follows. 
out of 17 groups), one subject remains steadfast in GROUP. It is reasonable to assume that the steadfast subjects remain steadfast in GROUPINFO because they might feel responsible for the outcomes and maybe even for avoiding the potential negative externalities. By postponing their switch, type Z groups increase socially responsible behavior.

\section{Result 2.2:}

There are two channels through which social information seems to increase social responsibility. First, there is a substantial share of around 40 percent of subjects that postpones accepting the negative externalities until potential gains are higher after observing the other subject trading. They might feel responsible for avoiding the negative externalities. Second, it seems as if at least some subjects do not want to be the first who switches to trade. As a result, some groups never choose trade.

\subsection{Market framing}

In the market framing treatment, the willingness to forego an own gain to avoid negative externalities drops. The MWTA decreases from 9.38 Euro to 5.04 Euro (see figure 1). After adding a market framing, a great majority of almost two thirds of the subjects chooses trade no later than in situation 2, as shown in figure 2. Relative to GROUPINFO, this is an increase of more than $50 \%$ in the acceptance of the negative externalities for 2.50 Euro. About 85 percent choose trade for 5.00 Euro or less in MFRAME.

The effect of market framing on the willingness to avoid negative externalities is significant (see table $5 ; p=0.0032$, Mann-Whitney $\mathrm{U}$ test, one-sided). The share of steadfast subjects decreases to 4.7 percent in MFRAME (see figure 2). It seems as if market framing makes it more difficult to remain steadfast ( $p=0.0404$, Mann-Whitney U test, one-sided). However, in a regression model, market framing decreases steadfastness insignificantly ( $p=0.117$ in the model of table 6 ).

\section{Result 3.1:}

Market framing decreases the willingness to avoid negative externalities. It also decreases the steadfastness.

A look inside the different types of groups supports alternative hypothesis 3, which posits that market framing decreases social responsibility. First, the share of type $\mathrm{X}$ groups, where the first subject already switches for potential gains of 0.00 or 2.50 Euro and the second subject follows immediately, decreases insignificantly from 40.6 in GROUPINFO to 31.3 percent in 
MFRAME ( $p=0.6029$, Mann-Whitney U test, two-sided). Type X's average MWTA does not decrease from GROUPINFO to MFRAME ( $p=0.6736$, Mann-Whitney $\mathrm{U}$ test, two-sided, $\mathrm{n}=23)$. Importantly, the average type S' MWTA is even lower than the average type X's MWTA, and there is a substantial increase in type $\mathrm{S}$ groups from 9.4 percent in GROUPINFO to 37.5 percent in MFRAME ( $p=0.0082$, Mann-Whitney U test, one-sided). As a large share of 91.7 percent of these type $\mathrm{S}$ groups (11 out of 12 groups) is purely self-interested, with an average MWTA of 2.50 Euro, these type S groups decrease the average MWTA substantially from GROUPINFO to MFRAME. In type $\mathrm{S}$ groups, both subjects switch to trade in the same situation, thus type $\mathrm{S}$ groups' subjects seem less likely to be affected by the information they receive about the other's behavior. In a sense, an increase in type $\mathrm{S}$ groups means that subjects become less sensitive to social information with a market framing. In contrast to all other treatments, with a market framing the selection of a purely self-interested strategy appears acceptable.

Type Y groups do not contain purely self-interested subjects, i.e., no subjects with a MWTA of 0.00 or 2.50 Euro. The share of type $\mathrm{Y}$ groups remains constant at a level of 9.4 percent in

MFRAME. However, the average MWTA of type Y groups decreases substantially from 24.53 Euro in GROUPINFO to 15.00 Euro in MFRAME ( $p=0.2270$, Mann-Whitney U test, one-sided, $\mathrm{n}=8)$.

In GROUPINFO, we find an interesting pattern. When the first subject switches to trade for low potential gains, the other subject might feel responsible for the outcomes and thus postpones switching to trade. The share of these type $\mathrm{Z}$ groups decreases from 40.6 percent in GROUPINFO to only 21.9 percent in MFRAME ( $p=0.0884$, Mann-Whitney U test, one-sided), i.e., when one side of the market proposes a profitable trade, it appears quite difficult for the other side to not accept immediately. Interestingly, the average MWTA of type Z groups decreases significantly from 13.46 Euro in GROUPINFO to 8.04 Euro in MFRAME ( $p=0.0285$, Mann-Whitney U test, one-sided, $n=20$ ), i.e., even if the other side does not accept immediately, it appears difficult for the second subject to not accept rather soon or even to remain steadfast when the other subject has already switched to trade in MFRAME. The share of type $\mathrm{Z}$ groups where one subject is steadfast decreases from 38.5 percent ( 5 out of 13 groups) in GROUPINFO to 14.3 percent (1 out of 7 groups) in MFRAME.

\section{Result 3.2:}

There are two channels through which market framing seems to decrease social responsibility. First, market framing seems to reduce the effect of social information; the share of groups that behave purely self-interestedly increases substantially. Second, without any market framing, there is a substantial share of about 40 percent of subjects that postpones accepting the negative externalities 
until potential gains are higher after observing the other subject trading. This share decreases with market framing. More subjects switch immediately, fewer subjects postpone accepting a trade and those subjects who postpone accept the trade for rather low potential gains. In particular, it appears difficult to remain steadfast with a market framing when the other one proposes a trade.

\subsection{Zooming into the efficiency threshold}

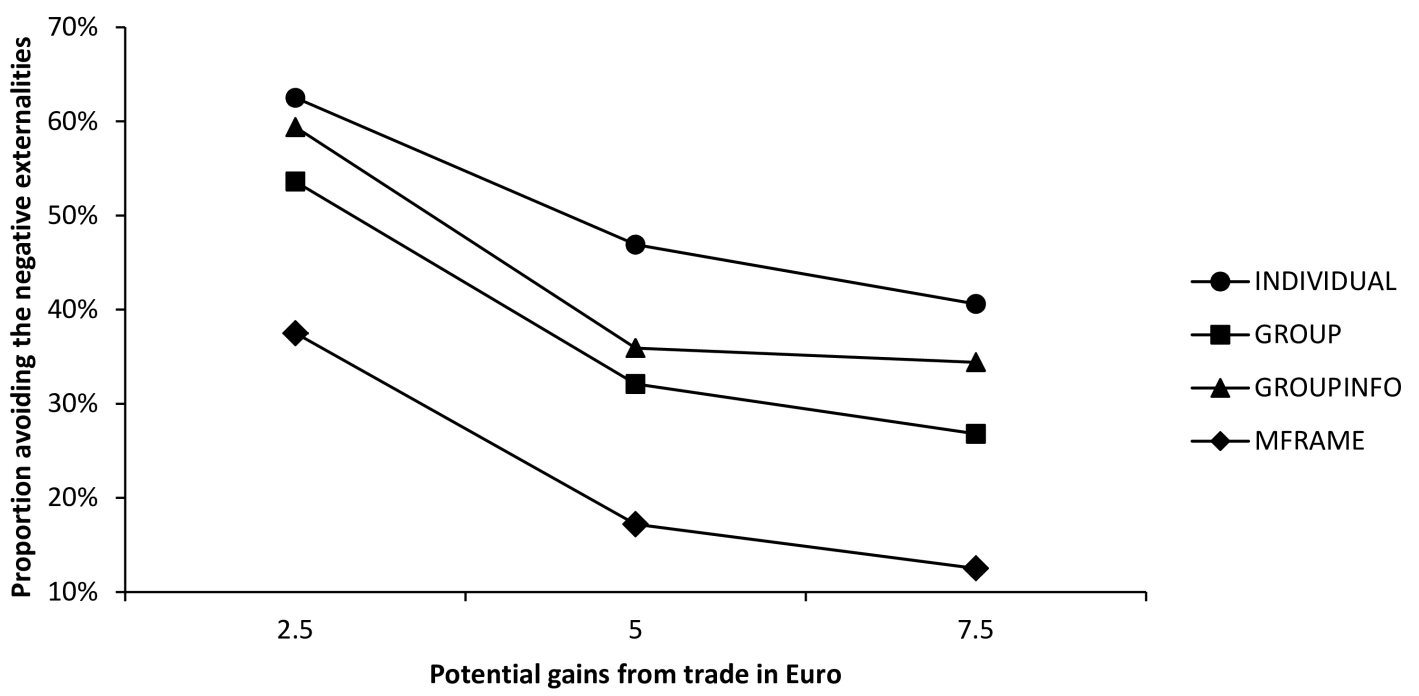

Figure 3 Average Individual No Trade Choices.

Figure 2 shows that a majority of subjects switches for low potential gains from no trade to trade. This is intuitive because the warm meal is worth only 5.20 Euro in monetary terms. When both subjects receive 5.00 Euro each, choosing trade is efficient. Our experiment is designed to better understand socially responsible behavior. We choose market interaction decision tasks with relatively small negative externalities to clearly disentangle subjects that do not switch because of steadfastness from subjects that do not switch due to efficiency considerations. Steadfast subjects remain steadfast, even if it is inefficient in monetary terms.

Figure 3 highlights the behavior for gains that are close to the monetary value of the warm meal by showing the proportion of no trade choices for situation 2, situation 3, and situation 4 (potential gains of 2.50 Euro to 7.50 Euro). In these situations, most subjects switch from no trade to trade. For example, in GROUP a majority of 53.6 percent of all subjects chooses no trade in situation 2, at a potential gain of 2.50 Euro. This share decreases to only 26.8 percent in situation 4 , at a potential gain of 7.50 Euro. When focussing on these particular situations, the observations 
are in line with our results presented above. INDIVIDUAL leads to the most socially responsible behavior, or the highest proportion of no trade choices. Diffusion of responsibility decreases the proportion of no trade choices, shifting the curve downward. Social information enhances the willingness to avoid negative externalities, and the curve shifts upward. Market framing shifts the proportion of no trade choice downward substantially.

\section{Conclusions}

Our study disentangles essential market characteristics to analyze their influence on socially responsible behavior. In our experiment, subjects can behave socially responsibly by preventing negative externalities that emerge when participants decide to trade. We model negative externalities by reducing donations to a charity that provides meals to needy children. We find that diffusion of responsibility tends to decrease the willingness to avoid negative externalities. Diffusion of responsibility also tends to decrease the share of steadfast subjects who never accept the negative externalities. Second, the effect of social information goes in the opposite direction. Social information increases the willingness to avoid negative externalities and even enables a substantial fraction of people to behave steadfastly. Third, concerns for the well-being of third parties drop dramatically due to market framing. It also seems to decrease subjects' ability to remain steadfast. If one side of the market proposes a profitable trade, within a market context it appears more difficult to refuse or postpone this trade. It seems that within a market framing subjects tend to condition their behavior to a lower degree on social information and they immediately go for the purely self-interested option. Overall, our findings show erosion of social responsibility in market interactions compared to individual decisions.

Our overall results are in line with Falk and Szech (2013), Bartling et al. (2015) and Kirchler et al. (2015). The market interaction modelled in their studies is influenced by all three market charateristics. In light of our results, the erosion of social responsibility is likely to be predominantly driven by a substantial market framing effect. The underlying mechanisms how market framing exactly erodes social responsibility needs further investigation. Is it, for example, that market framing narrows the focus on profit and distracts from the well-being of others? Or is it that market outcomes are generally considered as legitimate, maybe because positive features of markets such as promising efficient allocations of goods are generalized to a more or less unquestioned acceptability of market outcomes? Digging deeper into how market framing affects behavior might ultimately lead to suggestions of how to increase social responsibility of market participants. 


\section{References}

Bartling, Björn, Urs Fischbacher. 2012. Shifting the Blame: On Delegation and Responsibility. Review of Economic Studies 79(1) 67-87.

Bartling, Björn, Roberto A. Weber. 2013. Do Markets Erode Social Responsibility? University of Zurich Department of Economics Working Paper No. 134.

Bartling, Björn, Roberto A. Weber, Lan Yao. 2015. Do Markets Erode Social Responsibility? Quarterly Journal of Economics .

Besley, Timothy. 2013. What's the Good of the Market? An Essay on Michael Sandel's 'What Money Can't Buy'. Journal of Economic Literature 51(2) 478-495.

Breyer, Friedrich, Joachim Weimann. 2014. Of Morals, Markets and Mice: A Comment on Falk and Szech. CESifo Working Paper No. 4745 .

Clifford, Stephanie. 2013. Walmart Strains To Keep Aisles Stocked Fresh. The New York Times URL www. nytimes.com.

Cohn, Alain, Ernst Fehr, Michel André Maréchal. 2014. Business culture and dishonesty in the banking industry. Nature .

Conrads, Julian, Bernd Irlenbusch, Rainer Michael Rilke, Gari Walkowitz. 2013. Lying and team incentives. Journal of Economic Psychology 34 1-7.

Dana, Jason, Roberto A. Weber, Jason Xi Kuang. 2007. Exploiting moral wiggle room: experiments demonstrating an illusory preference for fairness. Economic Theory 33 67-80.

Düsseldorfer Tafel. 2013. Donate-A-Meal. URL http://www.donate-a-meal.com/.

Falk, Armin, Nora Szech. 2013. Morals and Markets. Science 340(6133) 707-711.

Fehr, Ernst, Klaus M Schmidt. 1999. A Theory of Fairness, Competition, and Cooperation. Quarterly Journal of Economics 114 817-868.

Fischbacher, Urs. 2007. z-Tree: Zurich toolbox for ready-made economic experiments. Experimental Economics 10(2) 171-178.

Government of Canada. 2015. Canada's Enhanced Corporate Social Responsibility Strategy to Strengthen Canada's Extractive Sector Abroad. URL http://www.international.gc.ca/.

Greiner, Ben. 2015. Subject Pool Recruitment Procedures: Organizing Experiments with ORSEE. Journal of the Economic Science Association 1(1) 114-125. URL http://link.springer.com/article/10. 1007/s40881-015-0004-4.

Kahneman, Daniel. 2003. Maps of Bounded Rationality: Psychology for Behavioral Economics. The American Economic Review 93(5) 1449-1475.

Kirchler, Michael, Jürgen Huber, Matthias Stefan, Matthias Sutter. 2015. Market Design and Moral Behavior. Management Science, forthcoming . 
Lefebvre, Mathieu, Pierre Pestieau, Arno Riedl, Marie Claire Villeval. 2014. Tax evasion and social information: an experiment in Belgium, France, and the Netherlands. International Tax and Public Finance

Sandel, Michael J. 2012. What Money Can't Buy. Farrar, Straus and Giroux, New York.

Shleifer, Andrei. 2004. Does Competition Destroy Ethical Behavior? The American Economic Review 94(2) $414-418$.

Suicides at Foxconn: Light and death. 2010. The Economist URL http://www.economist.com/.

Tversky, Amos, Daniel Kahneman. 1981. The Framing of Decisions and the Psychology of Choice. Science $211453-458$.

Tversky, Amos, Daniel Kahneman. 1986. Rational Choice and the Framing of Decisions. Journal of Business 59(4) 251-278.

Yankson, Paul W. K. 2010. Gold Mining and Corporate Social Responsibility in the Wassa West District, Ghana. Development in Practice 20(3) 354-366. 
Appendix. Implementation of the negative externalities

A. Online selection of the donated meals (examplary screenshot)

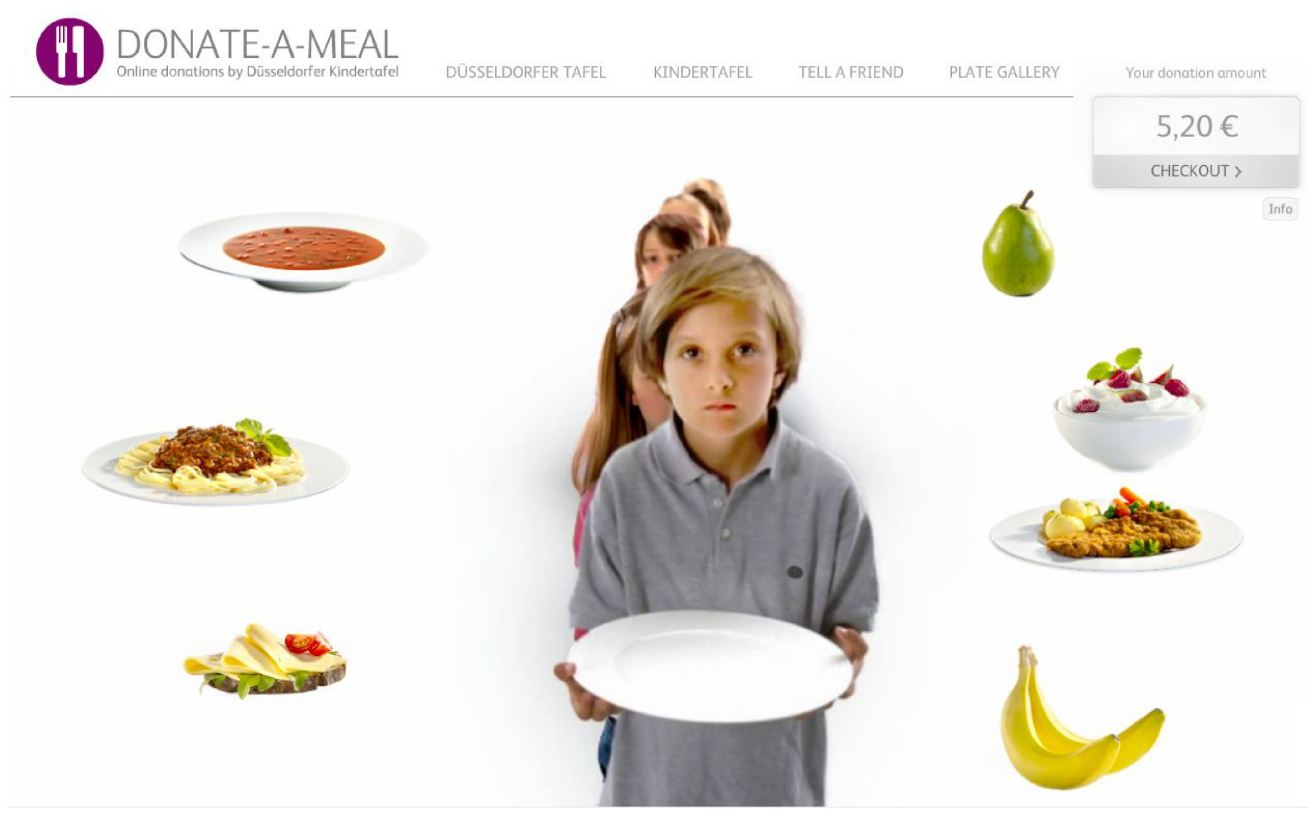

B. Removing meals from the default (examplary screenshot)

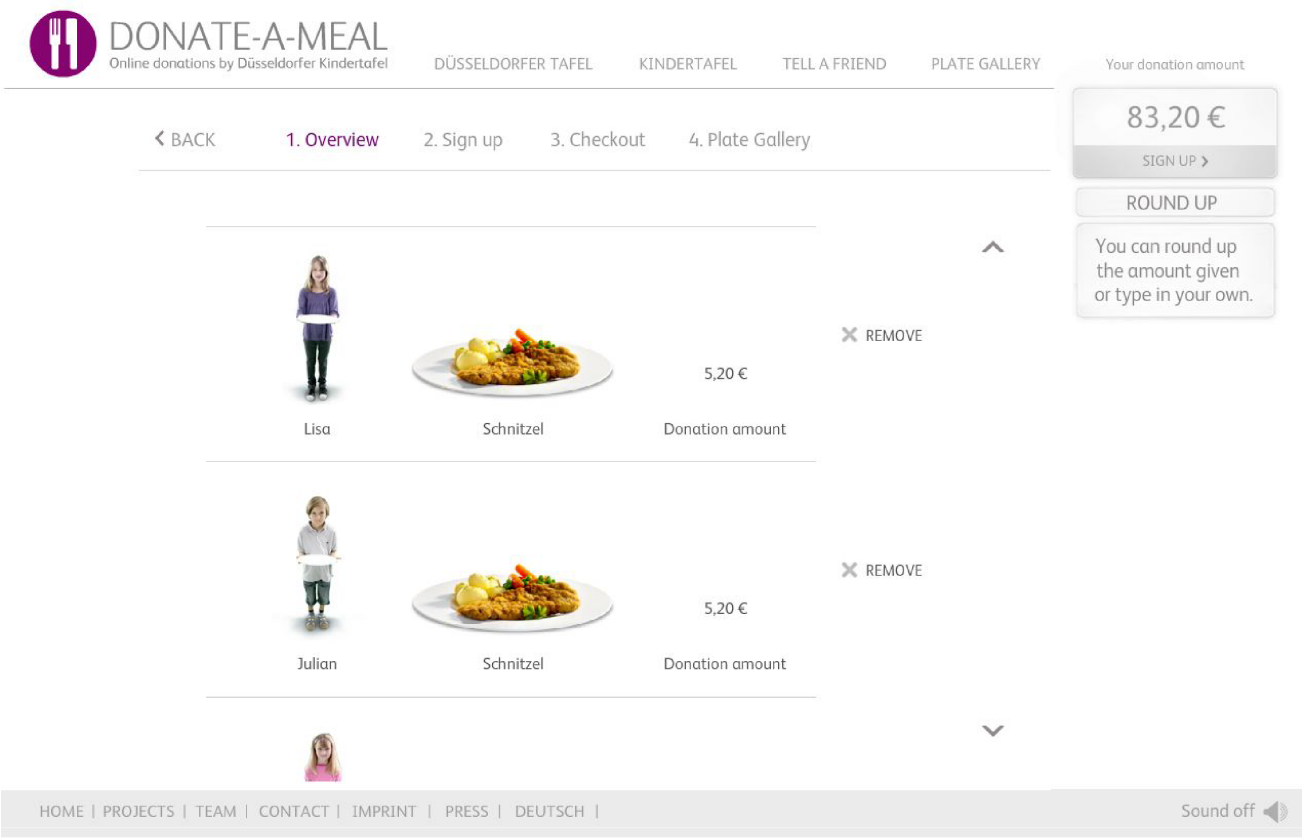

